\title{
Assessment of Groundwater Vulnerability in Azraq Catchment in Fuhais-Jordan Using DRASTIC Model
}

\author{
Hassan T. Khrisat1*, Jawad Al-Bakri² \\ ${ }^{1}$ Water Authority of Jordan, Amman, Jordan \\ ${ }^{2}$ The University of Jordan, Amman, Jordan \\ Email: *hassankhrisat@yahoo.com
}

How to cite this paper: Khrisat, H.T. and Al-Bakri, J. (2019) Assessment of Groundwater Vulnerability in Azraq Catchment in Fuhais-Jordan Using DRASTIC Model. Open Journal of Geology, 9, 364-377. https://doi.org/10.4236/ojg.2019.97024

Received: June 16, 2019

Accepted: July 26, 2019

Published: July 29, 2019

Copyright (อ 2019 by author(s) and Scientific Research Publishing Inc. This work is licensed under the Creative Commons Attribution International License (CC BY 4.0).

http://creativecommons.org/licenses/by/4.0/

\section{c) (i) Open Access}

\begin{abstract}
Groundwater resources in Jordan are under huge stresses. Accomplishing good water quality requires monitoring of water resources. Azraq spring considered the main source for drinking water of Fuhais City in Balqa governorate. The catchment area of the spring is less than $23 \mathrm{~km}^{2}$ and forms part of the side wadis feeding the groundwater basin in wadi Shuaib. This study aims to assess the vulnerability of groundwater to pollution that may result from agricultural activities and Fuhais wastewater treatment plant using GIS and DRASTIC model functions. Each symbol of the DRASTIC refers to one of the seven DRASTIC model parameters: Depth to water (D), Net recharge (R), Aquifer formation (A), Soil (S), Topography or slope (T), Impact of vadose zone (I) and Hydraulic conductivity (C). The final map of vulnerability showed 5 classes with different percent for each. These were: very low (5\%), low $(16 \%)$, moderate $(11 \%)$, high $(34 \%)$ and very high $(34 \%)$. In terms of area, the high and very high vulnerability classes distributed over $7.75 \mathrm{Km}^{2}$, while the low vulnerability distributed over $1.10 \mathrm{Km}^{2}$. Implementation of DRASTIC model showed increasing the vulnerability of ground water to contamination in the western part of study area because of the vadose zone and due to soil properties in this part of the study area. As such, vulnerability to pollution increased from the upstream area, where the treatment plant is located to the downstream area following the direction of flow and according to permeability. Water depth, net-recharge and media of aquifer had neglected effect of vulnerability map because it had one value at overall study area for each one. DRASTIC parameters could be arranged according to its effect on vulnerability map as $I>S>C>T>(D=R=A)$.
\end{abstract}

\section{Keywords}

Risk Assessment, GIS, DRASTIC, Vulnerability 


\section{Introduction}

Groundwater resources in Jordan are under huge stresses due to high population growth, and limited water resources due to deterioration of groundwater quality, and limited financial resources. Accomplishing good water quality requires monitoring of water resources. Azraq spring considered the main source for drinking water of Fuhais city. Average discharge of Azraq spring is around 1.4 MCM/Annual [1]. The contribution of Azraq spring to the drinking water of Fuhais and Mahis areas started to decline in the last two decades due to the increase in E-coli and nitrate [2]. Subsequently, Shuraia Station was constructed in year 2007 to treat the water of Azraq spring for the microbial contamination. This study aims to assess the vulnerability of groundwater to pollution that may result from agricultural activities and Fuhais wastewater treatment plants using DRASTIC model. The concept of groundwater vulnerability was first introduced in France by the end of the 1960s to create awareness of groundwater contamination [3].

Vulnerability assessment of groundwater aquifers provides a basis for initially protective measures for the main groundwater resources and will be the first step in an assessment of groundwater pollution hazard and groundwater quality, and to evaluate water quality in relation to land use changes and agricultural practices [4]. Groundwater vulnerability and protection has been emphasized as part of an integrated water resources management perspective [5]. The need for groundwater vulnerability assessment increases as sources of pollution are expanding within time and their impacts become complicated and interrelated. Aller et al., [6] were the first to introduce the DRASTIC modeling under US Environmental Protection Agency (US-EPA) for determination of pollution potential of aquifers. It was originally developed for manual overlay of semi-quantitative data layers, and it simply defined as a linear combination of factors shows the feasibility of the vulnerability computation using GIS [7].

All previous studies have pointed to the importance of mapping and assessing the impact of groundwater contamination and how it has contributed to reducing the deterioration of groundwater quality, resulting from the modern lifestyle, waste of agricultural activities and effluents for wastewater treatment plants, as evident through water quality tests. Therefore, this study will provide means for mapping and assessment of groundwater vulnerability in Wadi-Shuaib sub-basins based on available maps and data of water analysis by identifying factors affecting DRASTIC outputs so that negative impacts (if exist) coming from pollution sources are well identified and mapped.

\section{Study Area}

Azraq spring catchment forms part of the side wadis that feed wadi Shuaib groundwater basin. It is located in the northwestern part of Balqa, about $20 \mathrm{Km}$ west of Amman, about $1.3 \mathrm{Km}$ north of Fuhais and $1.2 \mathrm{Km}$ west of Hummar at $32.0205^{\circ} \mathrm{N}$ and $\mathrm{E}-35.7625^{\circ} \mathrm{E}$ (Figure 1). 


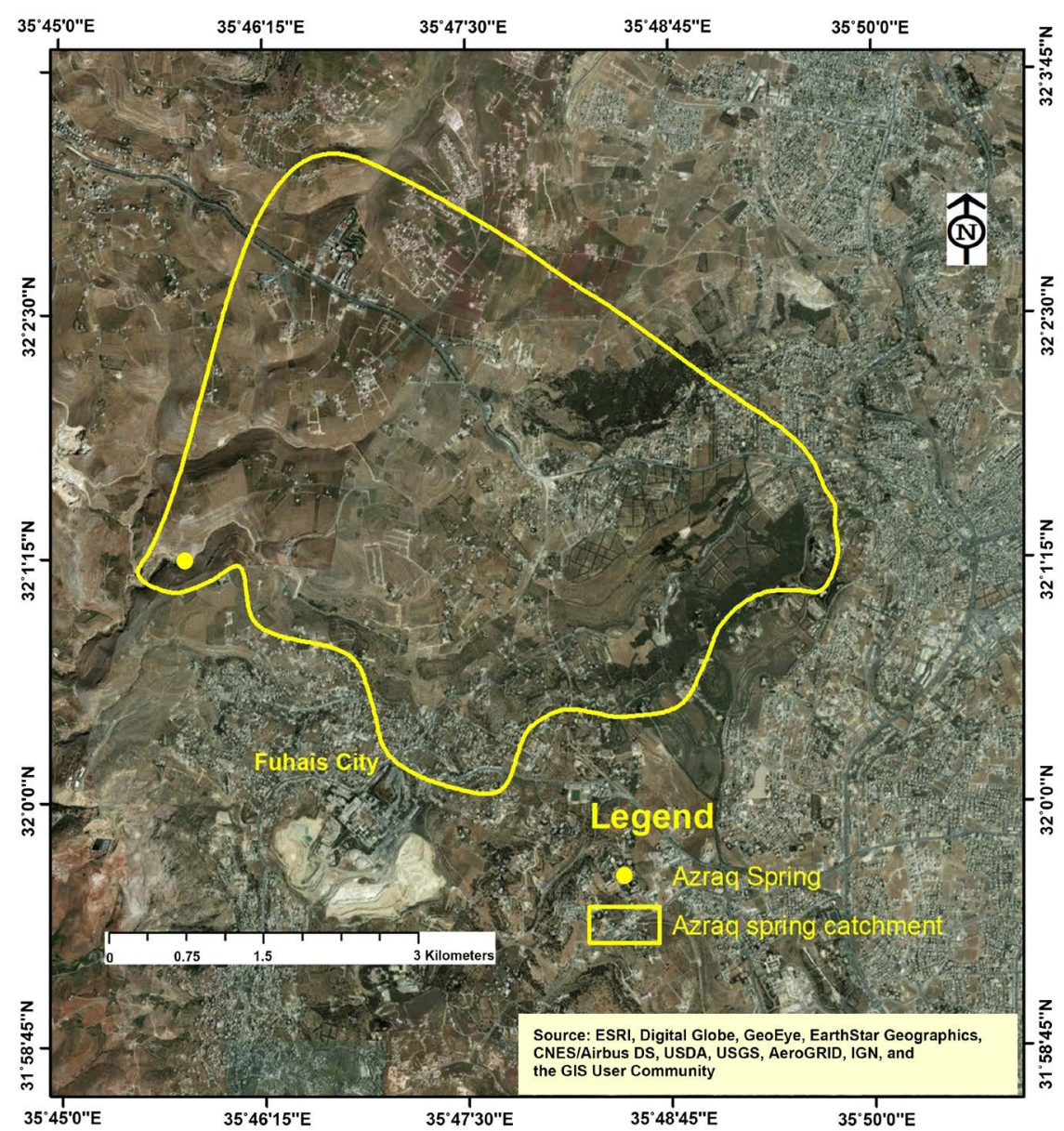

Figure 1. Location of the study area.

Azraq catchment area is $23.7 \mathrm{~km}^{2}$ and it has a perimeter of $20.4 \mathrm{~km}$. Azraq spring is originated from A7/B2 aquifer which is the most exploited aquifer in Jordan. It is a highly fractured-rock aquifer, consisting of sedimentary rocks (primarily carbonates and chert) from the late Cretaceous epoch. The fractures and other discontinuities such as joints, fissures and faults that occur in the rocks are allowing it to hold huge amounts of groundwater so it can be considered as a highly productive aquifer. The groundwater flow from the north-west to the south-east and flows from the north-east to the south-west, as shown in Figure 2. Surface water flow is from east and north to southwest.

\section{Methods}

Preparation of vulnerability map was attained through analysis of data gathered from different sources. Arc Map GIS based DRASTIC model was used to assess the vulnerability of groundwater to contamination.

In general, several methods are used to assess groundwater vulnerability depending on scale, data availability, and desired results. These include process-based methods, statistical methods, and overlay and index methods [8]. Process-based involves numerical modeling and it is only useful at the local level. Statistical 


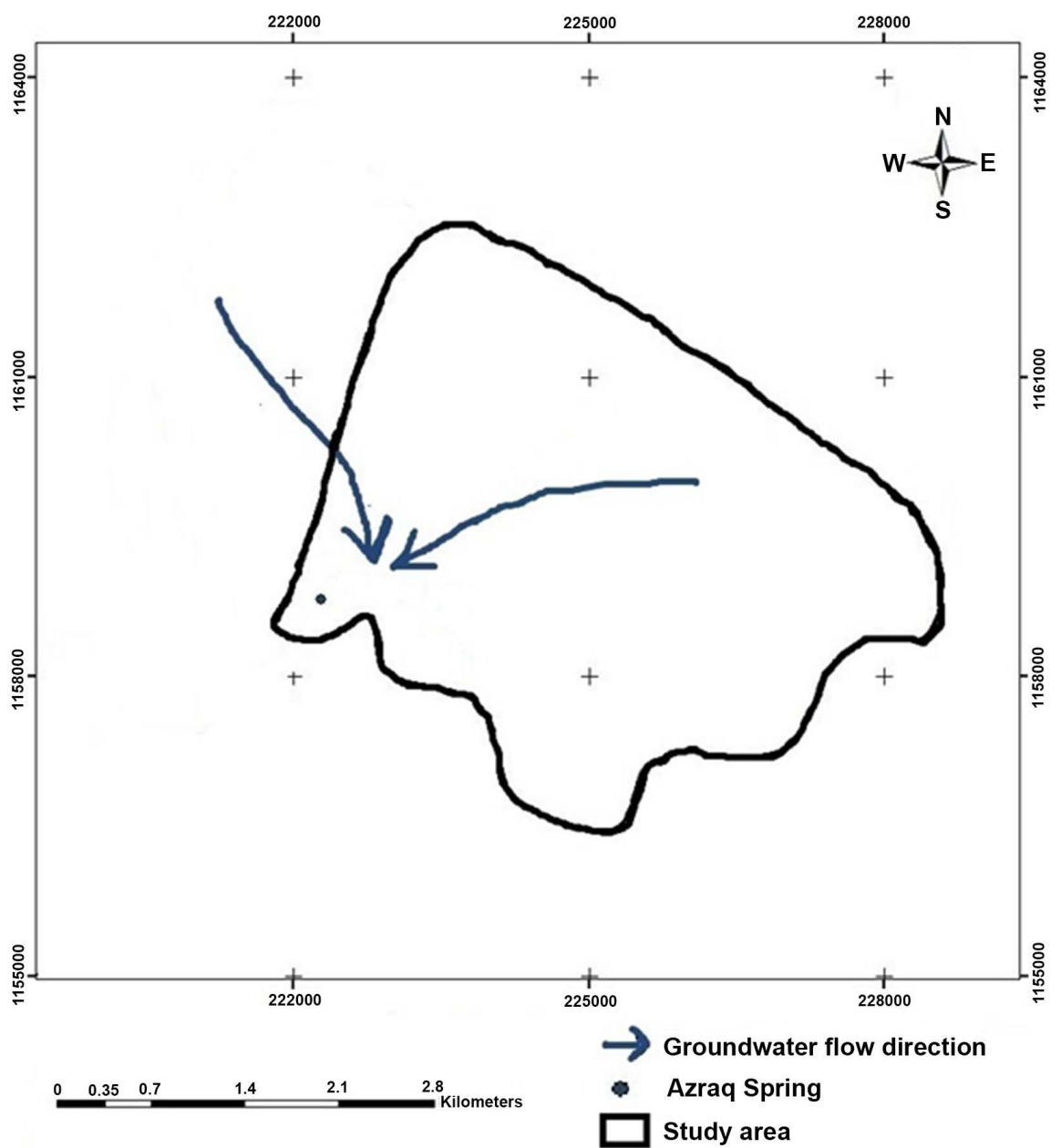

Figure 2. Groundwater flow direction.

methods involve correlating actual water quality data to spatial variables and require a large amount of site-specific data.

Overlay and index methods involve obtaining and combining maps of the parameters that affect the transport of contaminants from the surface to groundwater, then assigning an index [9]. This is more preferred over the first two methods as it adds spatial dimension to the outputs. This involves analyzing the DRASTIC parameters, calculating the DRASTIC index for the hydrogeological parameters, and rating these areas as to their vulnerability to contamination.

\section{Analyzing DRASTIC Model Parameters}

It included entering all DRASTIC parameters collected in previous steps (data collection, field survey and laboratory analysis) which required to calculate the DRASTIC Index. Each character of the DRASTIC abbreviation refers to one of the following seven DRASTIC model parameters: Depth to water (m), net Recharge (mm/day), Aquifer media, Soil media (soil order or soil texture), Topography (\%), Impact of vadose zone and Hydraulic conductivity $(\mathrm{m} / \mathrm{s})[6]$.

Depth of water layer was calculated by using GIS, firstly it required the use of 
interpolation tools to transfer contour shape file to digital elevation model (DEM), and using interpolation tool to interpolate static water level of well around study area that found in data base of MWI. Finally the depth of water is the difference between DEM and Static water level. Net recharge for the study area was calculated as a percentage of annual rainfall. Riepl [10], reported that net recharge equal $21 \%$ of annual rainfall. The rainfall layer was calculated by using interpolation tool for rainfall data for 13 rain stations around the study area. Aquifer media layer are calculated according to lithological description for wells around study area that are summarized in pumping test data.

Soil properties were derived from the soil maps of Jordan that had semi-detailed information for soil order/great group available at scales of 1:50,000 and 1:250,000 [11]. Properties of soil were obtained for two depths down to $40 \mathrm{~cm}$. Topography layer depended on DEM layer that was created for calculating depth of water. This required the conversion of DEM layer to slope layer which represented topography percentage by using slope-3D analyst tool. Impact of Vadose depended on geological formation that found in geological map for Wadi Shuaib. Hydraulic conductivity reflected permeability of aquifer formation which depended on hydrogeological classifications [12]. The value of permeability is an average for the minimum and maximum values for each formation. An interpolation was done for thee values to get the hydraulic conductivity overall study area.

\section{Calculating the DRASTIC Index}

DRASTIC index number for a given area is determined by multiplying each factor rating by its weight and adding together the resulting values as follows [13]:

$$
\text { DRASTIC Index }=\operatorname{DrDw}+R r R w+A r A w+S r S w+T r T w+I r I w+C r C w
$$

where $D, R, A, S, T, I$, and $C$ are the seven parameters of the DRASTIC method and subscripts $(r)$ and $(W)$ represent, respectively, the rating and weight of the parameters. The numerical rating $(r)$ varies from 1 to 10 that indicating the relative pollution potential of that factor for a given area as shown in Table 1. The weighting values $(w)$ varies from 1 to 5 represents the relative importance of each factor in its ability to affect pollution transport to and within aquifer, as shown in Table 2.

\section{Results}

In this part of study the result of each parameter of DRASTIC model for Azraq catchment is presented, so that important ones are identified for implementing the model for larger geographical extent in the study area.

\subsection{Depth of Water}

As shown in Figure 3, depth of water in overall area of catchment is more than $30.4 \mathrm{~m}$ that mean less potential to be contaminated. The study area has low rating $(r=1)$ according to the criteria shown in Table 1 . 
Table 1. Range and rating of the DRASTIC parameters used for Azraq Spring catchment.

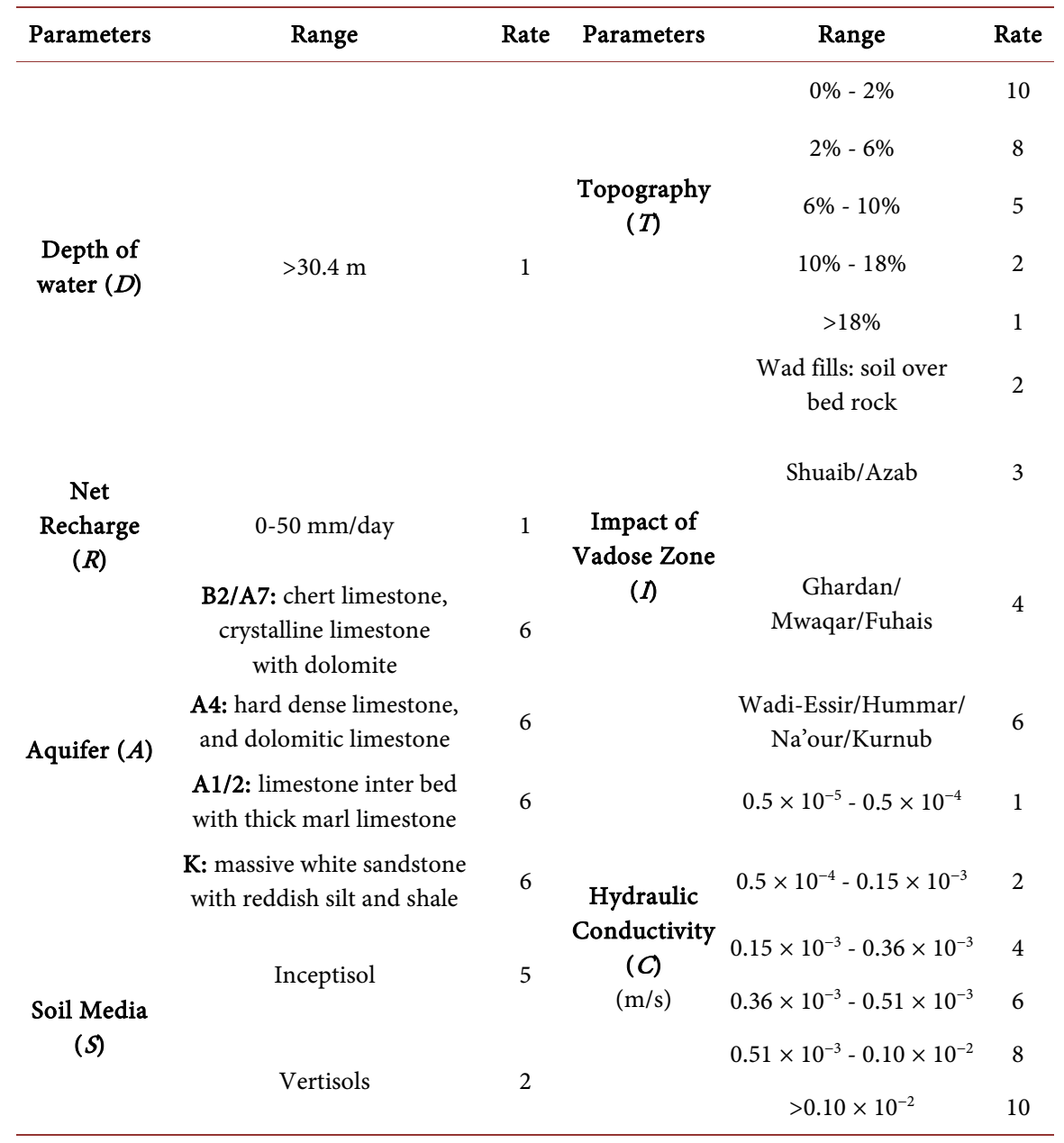

Table 2. Assigned weights for DRASTIC parameters [6].

\begin{tabular}{cc}
\hline DRASTIC Parameters & Weight \\
\hline Depth to Water $(D)$ & 5 \\
Net Recharge $(R)$ & 4 \\
Aquifer Media $(A)$ & 3 \\
Soil Media $(S)$ & 2 \\
Topography $(T)$ & 1 \\
Impact of Vadose Zone $(I)$ & 5 \\
Hydraulic Conductivity $(C)$ & 3 \\
\hline
\end{tabular}

\subsection{Net Recharge}

As mentioned above the net recharge reached $21 \%$ of annual rainfall. The average annual rainfall of study area is $538 \mathrm{~mm}$, calculated from Hummar stations that are located inside the catchment. Figure 4 shows the amount of net recharge represented in one category which is $0-50 \mathrm{~mm} /$ day. 


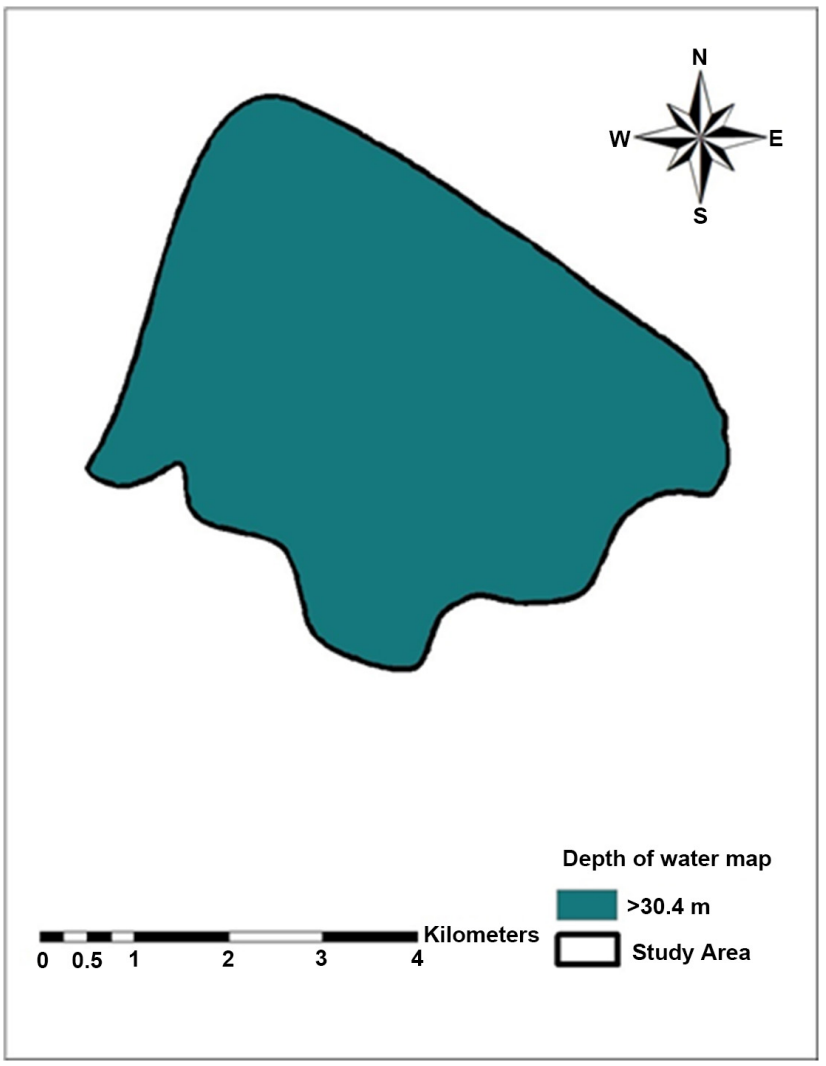

Figure 3. Depth of water.

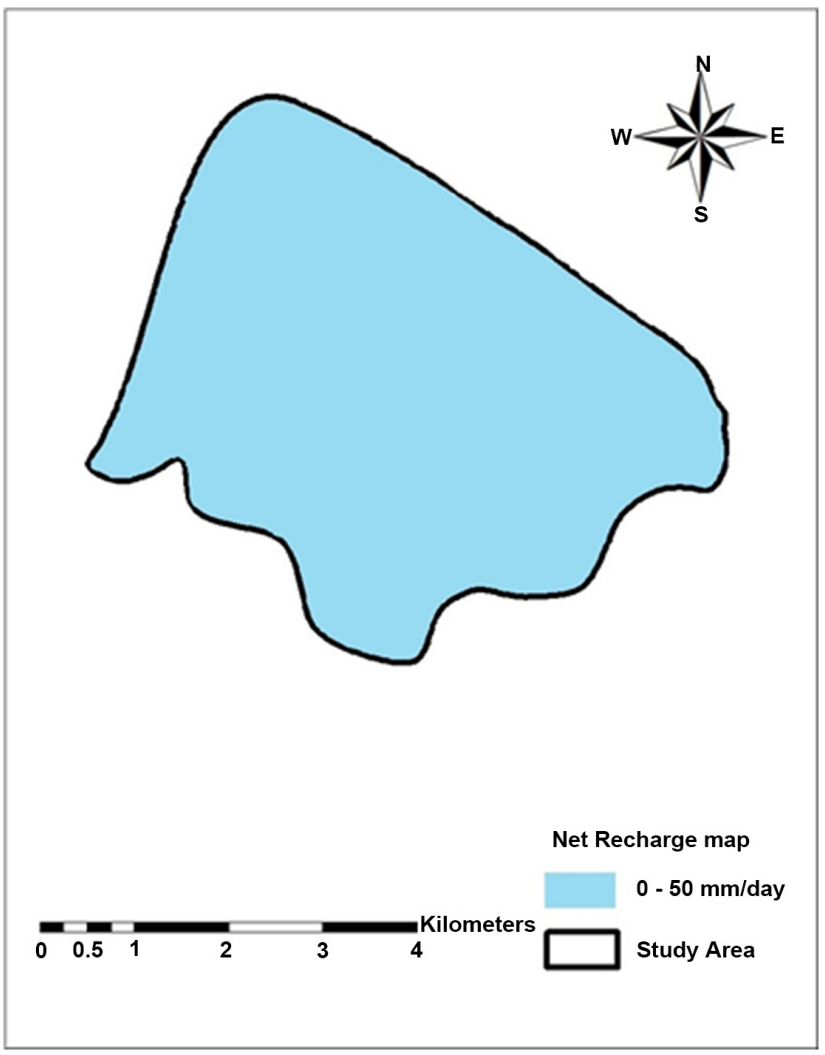

Figure 4. Net recharge. 


\subsection{Aquifer Media}

Four main aquifers are found in the study area: These are: B2/A7, A4, A1/2, and $\mathrm{K}$. the main rock is limestone (crystalline, dolomitic, and interbred) with some marl, massive white sandstone, reddish silt and shale. All these aquifers have the same rate (6), as shown in Figure 5.

\subsection{Soil}

The soil map shows that the catchment has two distinct soil orders. Two soil orders are found in catchment area as shown in Figure 6 . The highest rate is 5 for Inceptisols and lowest is 2 for Vertisols. The western part of catchment area has Inceptisols while the east part is dominated by Vertisols that had lower permeability than the other soil. The presence of Inceptisols permits polluted water to go through soil toward groundwater which increases the risk of contamination.

\subsection{Topography}

It is related with the graduate slope percentage over the study area. The highest slope has lowest rate because it has low effect in pollution and the lowest slope has a high rate, because the opportunity of pollution will increase. Figure 7 shows the variation in slope over study area.

\subsection{Impact of Vadose}

Four geological formations controlled the Vadose in the catchment (Figure 8).

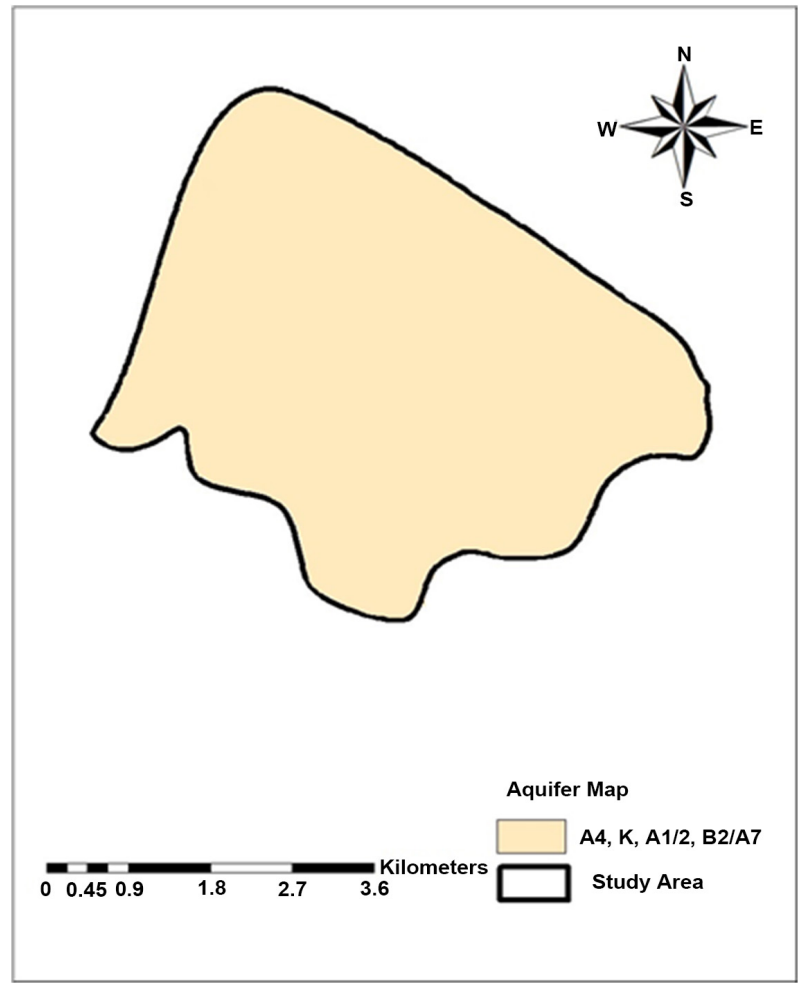

Figure 5. Aquifer media. 


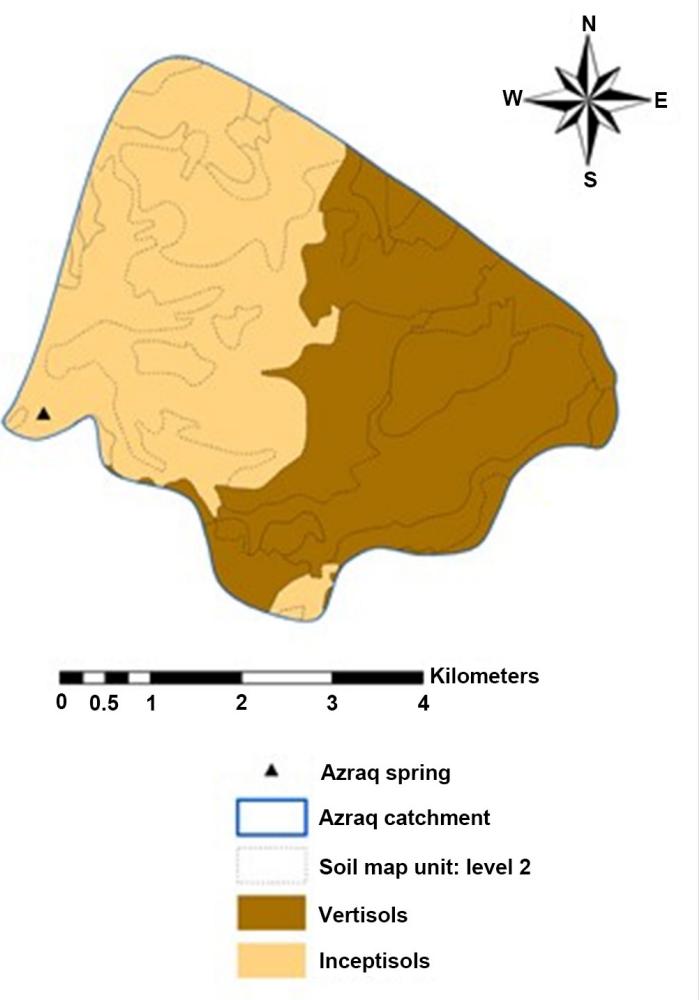

Figure 6. Soil map of the catchment.

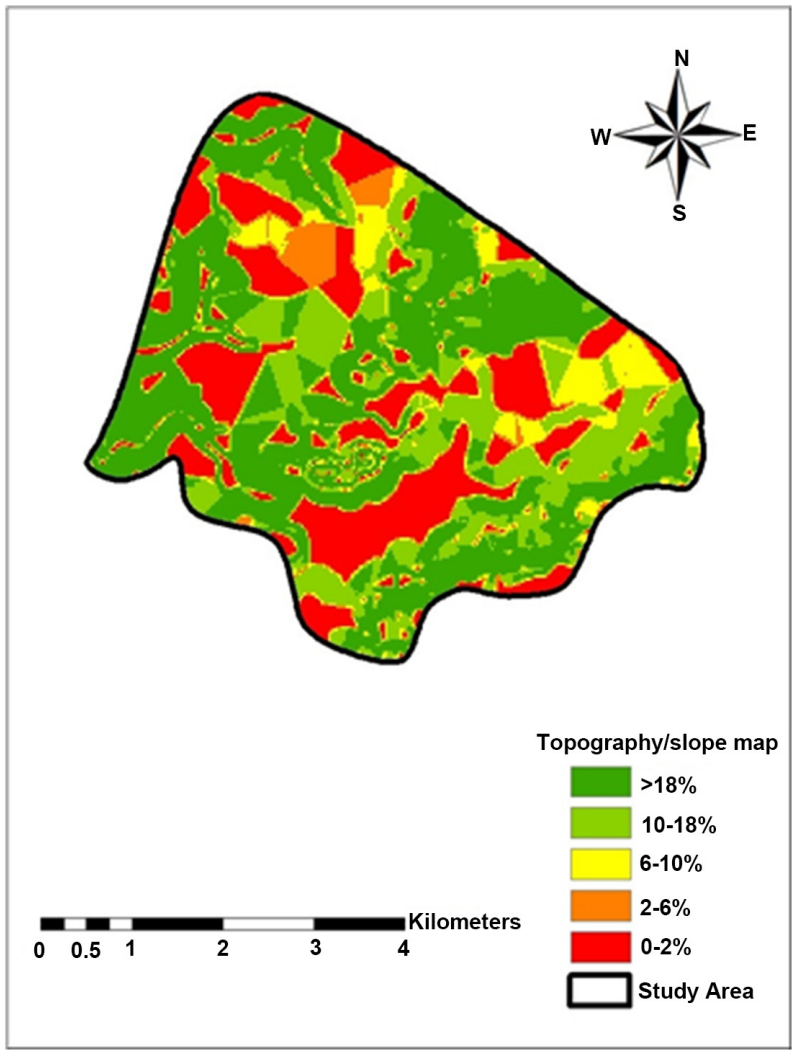

Figure 7. Topography of study area represented by the slope. 


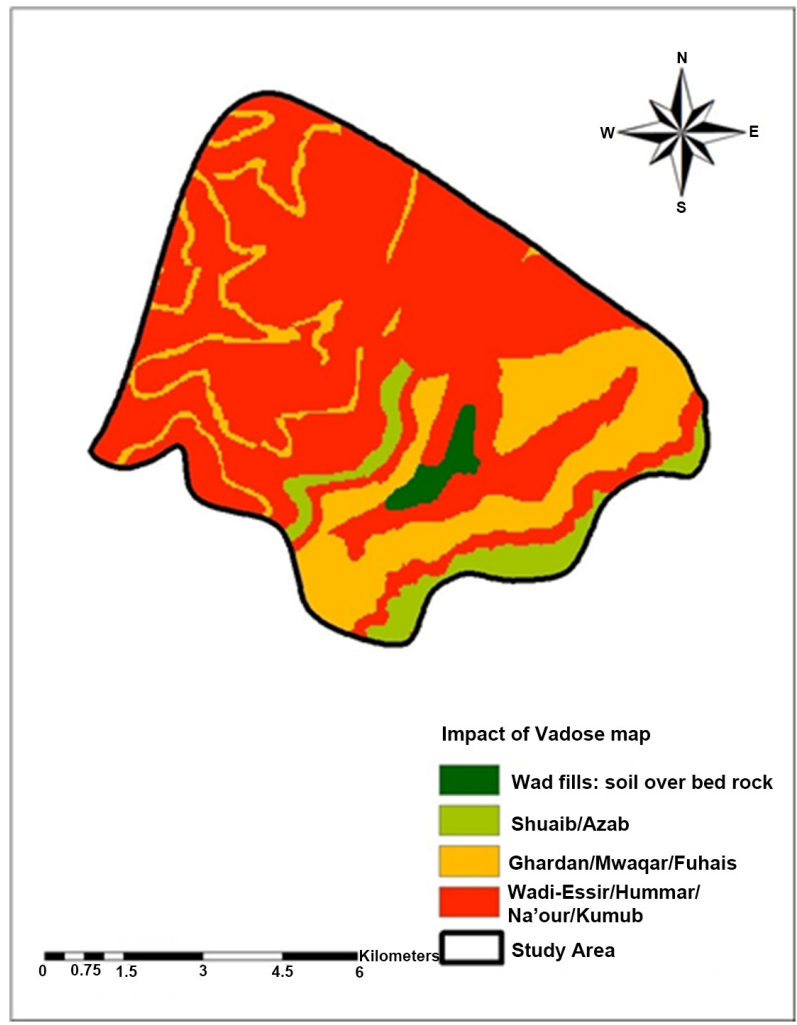

Figure 8. Impact of vadose.

The formations of Wadi Essir and Hummar were mainly limestone formations that had high rate (6) and dominated most of the catchment, while other formations in the middle and southwest of the study area had low rates ( 3 and 4).

\subsection{Hydraulic Conductivity}

Most of catchment area has high rate of hydraulic conductivity (10) that mean high risk to ground water because it has high permeability rate. The lowest rate (1) was found in small area of southern part of study area as shown in Figure 9.

\subsection{Vulnerability Map}

Final map of vulnerability showed 5 classes: very low, low, moderate, high, very high as shown in Figure 10. The very low has light color and the very high has dark color. The very high vulnerability (34\%) sites were mainly concentrated in the western parts of the study area, high vulnerability (34\%) areas were found in the northern and middle parts of the study area, while areas with low (16\% ) and very low (5\%) venerability were found in the northwestern and southeastern parts of the catchment. Moderate vulnerability class was scattered in different parts of the catchment. The areas with very high and high venerability extended over $7.75 \mathrm{Km}^{2}$ of the catchment, which was equivalent to $32 \%$ of the catchment's area, showing the that this catchment would be classified as a vulnerable area that would require careful planning and monitoring of groundwater resources used for drinking purposes. 


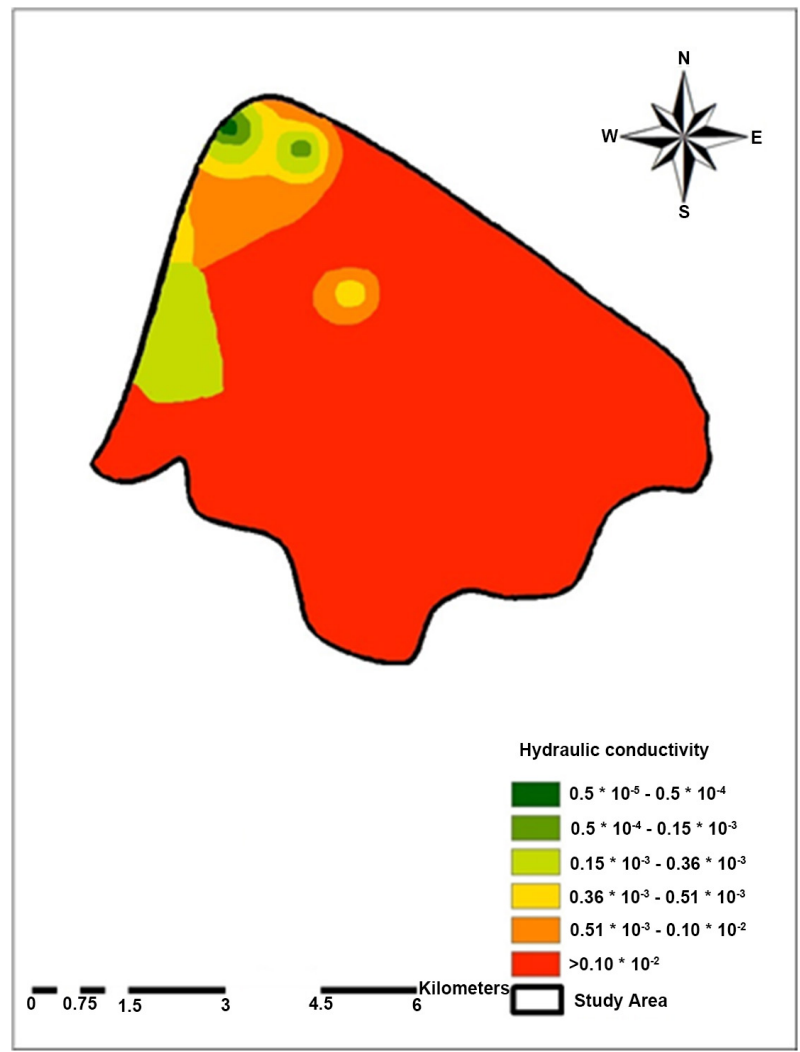

Figure 9. Hydraulic conductivity.

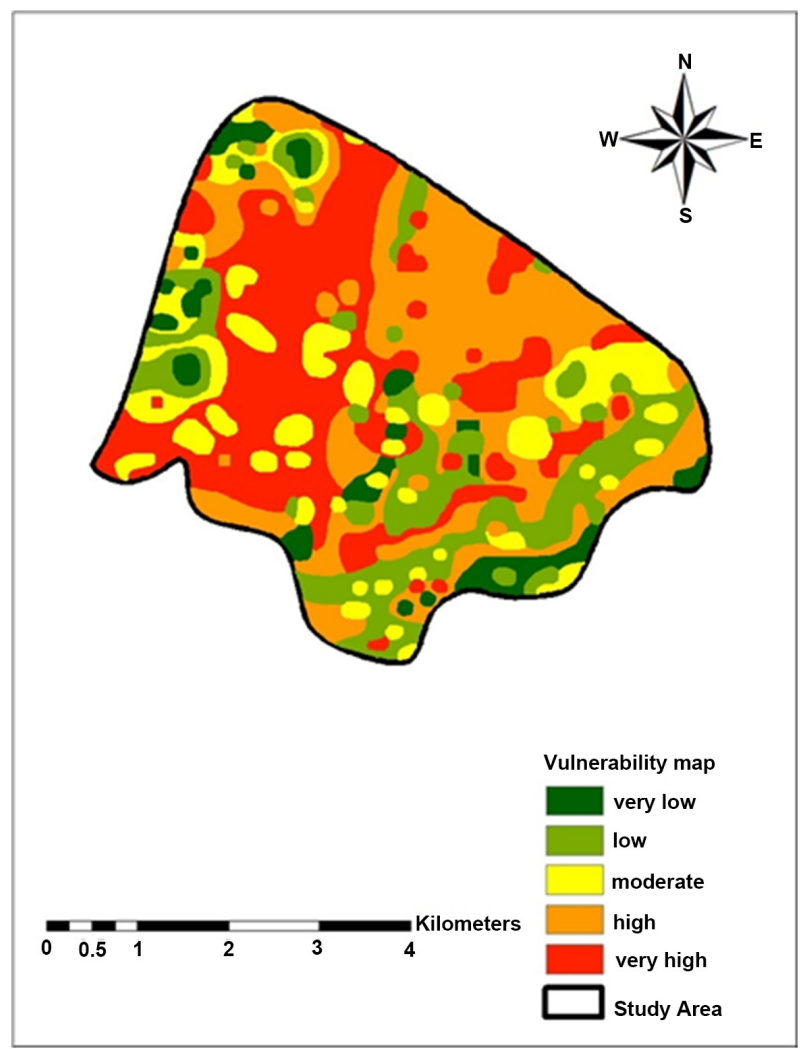

Figure 10. Final vulnerability map. 


\section{Discussion}

By reviewing to overall results of implementation of DRASTIC, the map of vulnerability reflected both of Vadose and hydraulic conductivity and to less extent the slope map. Other factors seemed to be equally reflected in this map. The vulnerability followed the flow direction in the catchment where pollution would increase when moving from the upstream area where the wastewater treatment plant is located to the downstream area where the water source of Azraq spring is utilized. This would mean more vulnerability to pollution at Azraq spring. Depth of water, Net Recharge and Aquifer media have neglected effect of vulnerability map because each had a single value all over the study area. DRASTIC parameters could be arranged according to its effect on vulnerability map as $I>$ $S>C>T>(D=R=A)$.

\section{Conclusion}

It can be concluded that the catchment of Azraq in Fuhais area would be classified as a vulnerable area that could be highly contaminated by the treated wastewater and other sources in the area. The areas with high vulnerability were identified by this work and would serve the purpose of groundwater monitoring in the catchment. Since no other detailed data was available the map would serve as an initial vulnerability map that could be refined with more detailed data in the future using the same criteria identified by this work. Also, it will require collecting water sampling in the Azraq catchment to validate the result of vulnerability map with results of water samples and the distribution of contamination, if available. Once validation is carried out and data of groundwater are obtained, the ratings may be modified accordingly and the approach can be generalized for the larger basin of Wadi Shuaib with all its sub-basins.

\section{Data Availability}

Some or all data, models, or code generated or used during the study are proprietary or confidential in nature and may only be provided with restrictions (e.g. maps and climatic data).

\section{Acknowledgements}

The authors acknowledge Water Authority of Jordan (WAJ) and the Ministry of Agriculture for supplying some of the data used in this research. Acknowledgment is also extended for the Open Journal of Geology for cooperation and inputs from anonymous reviewers.

\section{Conflicts of Interest}

The authors declare no conflicts of interest regarding the publication of this paper.

\section{References}

[1] Ministry of Water and Irrigation (2018) Water Year Book, Hydrological Year 2016-2017. 
$B G R, 31,31-41$

http://www.waj.gov.jo/sites/ar-jo/Documents/\%D8\%A5\%D8\%B5\%D8\%AF\%D8\%A 7\%D8\%B1\%D8\%A7\%D8\%AA\%20\%D9\%85\%D8\%A7\%D8\%A6\%D9\%8A\%D8\%A9 \%202018.pdf

[2] Abbassi, B.E., Khrisat, H. and Alnewashi, Q. (2009) Municipal Solid Waste Management at Salt City in Jordan: Community Perspective. Journal of Food, Agriculture \& Environment, 7, 740-745. https://www.wflpublisher.com/Abstract/2351

[3] Vrba, J. and Zaporozec, A. (1994) Guidebook on Mapping Groundwater Vulnerability. H. Heise, Hannover, Vol. 16, 119-131. https://trove.nla.gov.au/version/25583688

[4] Foster SSD (1987) Fundamental Concepts in Aquifer Vulnerability Pollution Risk and Protection Strategy. In: van Duijvenbooden, W. and van Waegeningh, H.G., Eds., Vulnerability of Soil and Groundwater to Pollutants, TNO Committee on Hydrological Research, The Hague, 69-86.

https://www.scirp.org/(S(czeh2tfqyw2orz553k1w0r45))/journal/PaperInformation.a spx?PaperID $=74513$

[5] El-Naqa, A. and Al-Shayeb, A. (2009) Groundwater Protection and Management Strategy in Jordan. Water Resources Management, 23, 2379-2394.

https://link.springer.com/article/10.1007/s11269-008-9386-x https://doi.org/10.1007/s11269-008-9386-x

[6] Aller, L., Bennet, T., Leher, J.H., Petty, R.J. and Hackett, G. (1987) DRASTIC: A Standardized System for Evaluating Groundwater Pollution Potential Using Hydro Geological Setting. EPA, 35, 600-622.

https://link.springer.com/article/10.1007/s11269-008-9319-8

[7] Napolitano, P. and Fabbri, A. (1996) Single-Parameter Sensitivity Analysis for Aquifer Vulnerability Assessment Using DRASTIC and SINTACS. In: HydroGIS 96: Application of Geographical Information Systems in Hydrology and Water Resources Management, Proceedings of Vienna Conference, IAHS Pub., Vienna, No. 235, 559-566. http://hydrologie.org/redbooks/a235/iahs_235_0559.pdf

[8] Tesoriero, A.J., Inkpen, E.L. and Voss, F.D. (1998) Assessing Ground Water Vulnerability Using Logistic Regression. Proceedings for the Source Water Assessment and Protection 98 Conference, Dallas, TX, 157-165.

http://citeseerx.ist.psu.edu/viewdoc/download?doi=10.1.1.540.2733\&rep=rep1\&type $=\mathrm{pdf}$

[9] National Research Council (1993) Ground Water Vulnerability Assessment: Predicting Relative Contamination Potential under Conditions of Uncertainty. The National Academies Press, Washington DC, 224 p.

https://www.nap.edu/catalog/2050/ground-water-vulnerability-assessment-predicti $\underline{\text { ng-relative-contamination-potential-under-conditions }}$

[10] Riepl, D. (2013) Knowledge-Based Decision Support for Integrated Water Resources Management with an Application for Wadi Shueib, Jordan. Published Doctoral Dissertation, Karlsruhe Institute for Technology (KIT), University of the State of Baden-Wuerttemberg and National Research Center in the Helmholtz Association, Wuerttemberg. http://www.iwrm-smart-move.de/images/smartmove/deliverables/smart2

[11] Al-Bakri, J.T. (2008) Soils of Jordan. In: Zdruli, P. and Trisorio Liuzzi, G., Eds., Status of Mediterranean Soil Resources: Actions Needed to Support Their Sustainable Use, Mediterranean Conference Proceedings, Tunis, Tunisia 26-31 May 2007, MEDCOASTLAND Publication, IAM Bari, Italy, 368. 
[12] Rimawi, O. (1985) Hydrochemistry and Isotope Hydrology of Groundwater and Surface Water in the North-East of Mafraq, Dhuleil, Hallabat, Azraq Basin. Ph.D. Thesis, Technische Universität München.

https://scholar.google.com/scholar?cluster=13227143089980320363\&hl=en\&oi=sch olarr

[13] Hammour, N. and El-Naqa, A. (2008) GIS Based Hydrogeological Vulnerability Mapping of Groundwater Resources in Jerash Area-Jordan. Geophysics International, 47, 85-97.

https://www.semanticscholar.org/paper/GIS-based-Hydrogeological-VulnerabilityMapping-of-Hammouri-El-Naqa/4bbd28a29186066430604717f9aaea1388237314. 